\title{
FIELD MEASUREMENTS OF SHEET FLOW SEDIMENT TRANSPORT IN THE SWASH ZONE
}

\author{
Thijs Lanckriet ${ }^{1}$, Jack A. Puleo ${ }^{1}$, Gerd Masselink ${ }^{2}$, Ian Turner ${ }^{3}$, Daniel Conley ${ }^{2}$, Chris \\ Blenkinsopp $^{3}$ and Paul Russell ${ }^{2}$
}

\begin{abstract}
A newly developed Conductivity Concentration Profiler (CCP), capable of rendering a 29-point sediment concentration profile at $1 \mathrm{~mm}$ vertical resolution, was deployed on a macrotidal beach in Perranporth, UK, as part of a comprehensive field study on swash zone hydrodynamics and sediment transport. Initial field results show the occurrence of sheet flow during both the uprush and backwash phases of the swash cycle. Concentration profiles in the sheet flow layer are approximately linear, with a power-law tail at the top of the layer. The data suggest that shear stresses are the dominant forcing for sediment mobilization, but pressure gradients provide a secondary mobilization mechanism.
\end{abstract}

Keywords: swash zone, sediment transport, sheet flow

\section{INTRODUCTION}

Sediment transport magnitudes in the swash zone are among the highest in the coastal area. One of the main reasons for the high sediment loads is the frequent occurrence of sheet flow, a process in which a sand-water slurry with a thickness on the order of tens to hundreds of grain diameters moves across the beach face (Hughes et al. 1997). Sheet flow can easily be observed visually during the backwash of many swash events, but due to its rapidly shallowing depth is much harder to measure in detail and is therefore often neglected (by necessity) in field measurements. The collection of sheet flow and bedload sediment transport data from the field was identified as a key element to improve the understanding of swash zone sediment dynamics and morphology (Masselink and Puleo 2006).

Sediment is usually mobilized by shear stresses exerted by the fluid on the bed. The onset of sheet flow and the thickness of the sheet layer are described using the Shields number $\theta$ :

$$
\theta=\frac{\tau_{b}}{\left(\rho_{f}-\rho_{s}\right) g d}
$$

where $\tau_{b}$ is the shear stress exerted on the bottom, $\rho_{f}$ is the fluid density, $\rho_{s}$ is the sediment density, $g$ is gravitational acceleration and $d$ is a representative grain diameter. Sheet flow occurs when the Shields number exceeds a threshold of 1.0 (Nielsen 1992). The thickness of the sheet layer $\delta_{s}$ is parameterized as (Wilson 1987)

$$
\frac{\delta_{s}}{d}=10 \theta
$$

Sheet flow as a sediment transport process has been studied in detail in several scaled laboratory studies (Dohmen-Janssen and Hanes 2005; Horikawa et al. 1982; O'Donoghue and Wright 2004; Pugh and Wilson 1999; Ribberink and Al-Salem 1995), as well as in numerical studies (Amoudry et al. 2008; Drake and Calantoni 2001). In most laboratory studies the sediment concentration in the sheet layer is determined by measuring the electrical conductivity of the sand-water mixture. Many of these studies, however, collect only one or a few point measurements of sediment concentration and construct a concentration profile by performing each experiment multiple times under repeatable conditions. This approach is not possible under field conditions with irregular waves. Only very limited field measurements are available of sediment concentration in the sheet flow layer (Bakker et al. 1988; Yu et al. 1990). Recently, a new Conductivity Concentration Profiler (CCP) instrument was developed that is capable of rendering a real-time sediment concentration profile in the sheet flow layer under large-scale laboratory and field conditions (Lanckriet et al., in review).

This paper presents initial field results using the CCP during a field deployment in Perranporth, UK, in October 2011 (see also Puleo et al., this volume). The measurement characteristics of the CCP will be reviewed first and this is followed by a description of the field study. Results of the measurements using the $\mathrm{CCP}$ are then presented, followed by conclusions.

\footnotetext{
${ }^{1}$ Center for Applied Coastal Research, University of Delaware, Newark, DE 19716, USA

${ }^{2}$ School of Marine Science and Engineering, Plymouth University, Drake Circus, Plymouth, PL4 8AA, UK

${ }^{3}$ Water Research Laboratory, School of Civil and Environmental Engineering, University of New South Wales, Sydney NSW 2052, Australia
} 


\section{THE CONDUCTIVITY CONCENTRATION PROFILER}

Since water has a high electric conductivity and non-cohesive sediments are essentially nonconductive, the presence of sediment in a sediment-water mixture will obstruct electrical current and reduce the bulk electrical conductivity. As a result, it is possible to determine the sediment concentration by measuring the reduction in electrical conductivity with respect to the clear fluid. This technique is particularly successful in high-concentration conditions such as the sheet flow layer (Horikawa et al. 1982), where alternative measurement techniques (e.g., acoustic or optical methods) do not yield an accurate concentration measurement.

The Conductivity Concentration Profiler (CCP) is the first instrument for measuring sediment concentration using electrical conductivity that was specifically developed for large-scale laboratory and field conditions (Lanckriet et al. in review). It measures conductivity using a 4-electrode approach (Li and Meijer 2005) and obtains a 29-point concentration profile with $1 \mathrm{~mm}$ resolution by multiplexing through an array of 32 measurement electrodes. Only a small part of the CCP, with a cross section of $5.6 \mathrm{~mm}$ (width) by $1.6 \mathrm{~mm}$ (thickness) and a height above the bed on the order of 10$40 \mathrm{~mm}$ (varying as the bed level changes), is exposed to the flow, minimizing flow disturbance and scour effects.

The relationship between sediment concentration and conductivity was established by a laboratory experiment where sediment was suspended neutrally in a Lithium Metatungstate (LMT) solution with a density approximately equal to the density of the sediment. For two sediment samples, a fine sand $\left(d_{50}\right.$ $=0.12 \mathrm{~mm})$ and a coarse sand $\left(d_{50}=0.44 \mathrm{~mm}\right)$, the sensor response was well described $\left(r^{2}>0.98\right)$ by a power law known as Archie's law (Archie 1942):

$$
\sigma_{m} / \sigma_{f}=(1-c)^{m}
$$

where $\sigma_{m}$ is the conductivity of the sand-fluid mixture, $\sigma_{f}$ is the conductivity of the fluid, $c$ is the sediment volume fraction and $m$ is a calibration factor.

The measurement volume of the CCP was determined by modeling the electric current and voltage field around the sensor using a finite differences model. In the two principal horizontal axes, the representative measurement volume extends $8.7 \mathrm{~mm}$ and $8.4 \mathrm{~mm}$ away from the center of the probe axis (roughly 1.5 times the probe width). In the vertical direction, the finite extent of the measurement volume causes smoothing of the measured concentration profile. The impact of this smoothing was assessed by running the finite differences model for a simulated sheet layer with varying thickness. The difference between the sheet layer thickness as prescribed in the model geometry and the thickness perceived by the simulated CCP was used to determine that the minimum sheet thickness that can reliably be resolved by the CCP is $3.5 \mathrm{~mm}$. For sheet thicknesses larger than $3.5 \mathrm{~mm}$, a correction formula was developed to account for the smoothing effect (Lanckriet et al., in review).

\section{FIELD STUDY}

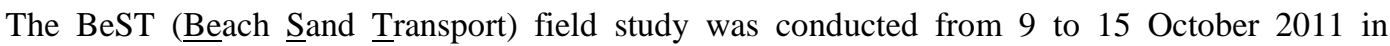
Perranporth, UK, with the aim of rendering a complete dataset of swash zone hydrodynamics and sediment transport under field conditions. Measurements were taken around high tide during 10 tidal cycles around spring tide (mean tidal range is $5.43 \mathrm{~m}$ ). The study site is a macrotidal dissipative beach with a median grain size $d_{50}$ of $0.33 \mathrm{~mm}$ and a mean slope of 1:45 around the measurement rig. Only results from the evening high tide of October 14 are discussed here; further details on the field study, the study site and the entire suite of instruments deployed are described in Puleo et al. (this volume).

During the high tide discussed in this contribution, three CCPs were deployed at a single crossshore location, spaced by approximately $0.2 \mathrm{~m}$ in the alongshore and offset in the vertical to account for bed-level changes (Figure 1). One of the three sensors remained buried under the mobile-bed layer during the entire high tide and will not be discussed here. Additionally, velocities were measured using 2 Valeport electromagnetic current meters that were positioned $0.03 \mathrm{~m}$ and $0.06 \mathrm{~m}$ above the bed, and water levels were measured using an ultrasonic distance meter (Massa M300/95). The CCPs, electromagnetic current meters and ultrasonic distance meters were all sampled at $4 \mathrm{~Hz}$. The offshore significant wave height and spectral peak period recorded by a Waverider buoy located in $10 \mathrm{~m}$ water depth at less than $2 \mathrm{~km}$ from the study site were $0.55 \mathrm{~m}$ and $9.1 \mathrm{~s}$ respectively. 


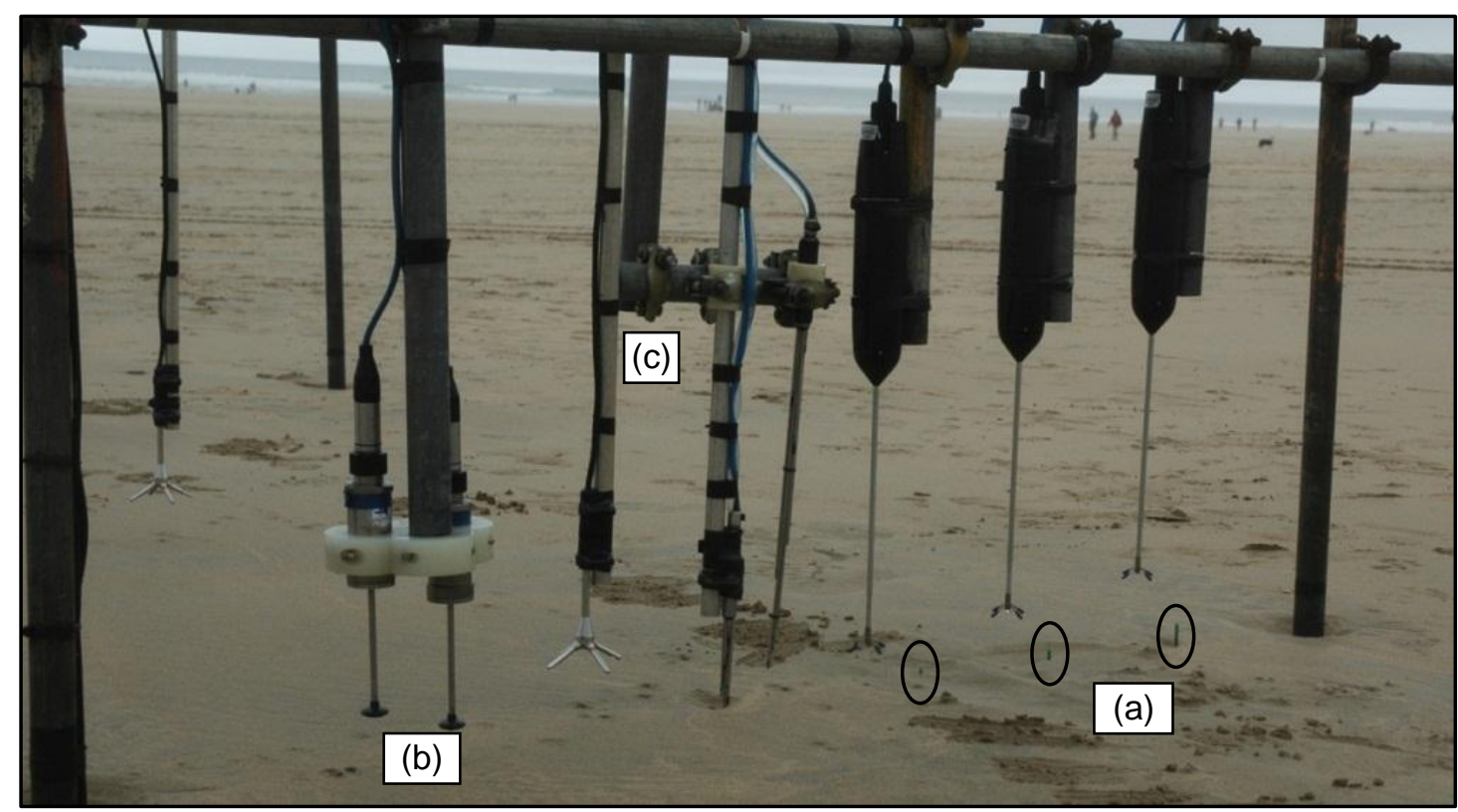

Figure 1. Deployment of the main swash rig with 3 buried CCPs (a), 2 electromagnetic current meters (b) and an ultrasonic distance meter (c), behind the pole.

\section{RESULTS}

Figure 2 displays an example swash event in which a single bore impinges on the sensor location, resulting in a swash duration of $26 \mathrm{~s}$ and a maximum water depth of $0.11 \mathrm{~m}$. The maximum uprush velocity is $1.7 \mathrm{~m} \mathrm{~s}^{-1}$ (as measured using the current meter deployed $0.03 \mathrm{~m}$ above the bed) and the backwash velocity reached $-1.4 \mathrm{~m} \mathrm{~s}^{-1}$ shortly before the water level fell below the sensor elevation.

Figure $2 \mathrm{~d}$ displays the sediment concentration measurements taken by one CCP. A cut-off volume fraction of 0.08 was chosen to define the top of the sheet layer and 0.51 for the bottom (Bagnold 1966), which are displayed as a dashed and solid line in Figure 2d respectively. The section of the profile with volume fractions less than 0.08 is then considered to be in the suspension layer and the section with volume fractions over 0.51 to be in the stable bed. The elevation difference between the top and bottom of the sheet layer is then taken as the thickness of the sheet layer and is corrected for the smoothing effect using the correction formula derived from the numerical experiments with the finite differences model (Lanckriet et al., in review).

Around flow reversal $(t=9.1 \mathrm{~s})$, the cut-off concentrations 0.08 and 0.51 are separated by $5 \mathrm{~mm}$ in the CCP measurements. As there is no hydrodynamic forcing during flow reversal, there is no sheet layer present and the perceived distance between the top and bottom cut-off concentration is due to sensor smoothing. The numerical simulations that were used to study the sensor smoothing effect similarly show a smoothing effect on the order of 4 to $5 \mathrm{~mm}$ for a case with no sheet flow layer (Lanckriet et al., in review). During both the uprush and backwash, however, the distance between the top and bottom cut-off concentration becomes larger, indicating the presence of a sheet flow layer. During the uprush, a short-lived sheet flow occurs with a maximum thickness of $19 \mathrm{~mm}(0 \mathrm{~s} \leq t \leq 4 \mathrm{~s})$. During the backwash, the sheet flow has a smaller maximum thickness of $8 \mathrm{~mm}$ but a longer duration $(12.5 \mathrm{~s} \leq t \leq 25 \mathrm{~s})$.

The resulting sheet thickness was calculated for two CCPs which were located in the same crossshore position and separated by approximately $0.2 \mathrm{~m}$ in the alongshore (Figure $2 \mathrm{c}$ ). The time series of corrected sheet thickness agree well between the two sensors, indicating repeatability of the measurements.

Figure 3 displays instanteneous vertical sediment concentration profiles, measured at two instances during the example swash event (indicated by dash-dotted lines in Figure 2d), one during the uprush and one during the backwash. Again, the agreement between the measurements by the two collocated sensors demonstrates repeatibility. The concentration profile in the sheet layer appears to be mostly linear, with a power-law tail at the top of the sheet layer where the sheet flow transitions into the suspended load regime. This profile shape is in agreement with previous experiments on unidirectional sheet flow (Pugh and Wilson 1999; Sumer et al. 1996). 

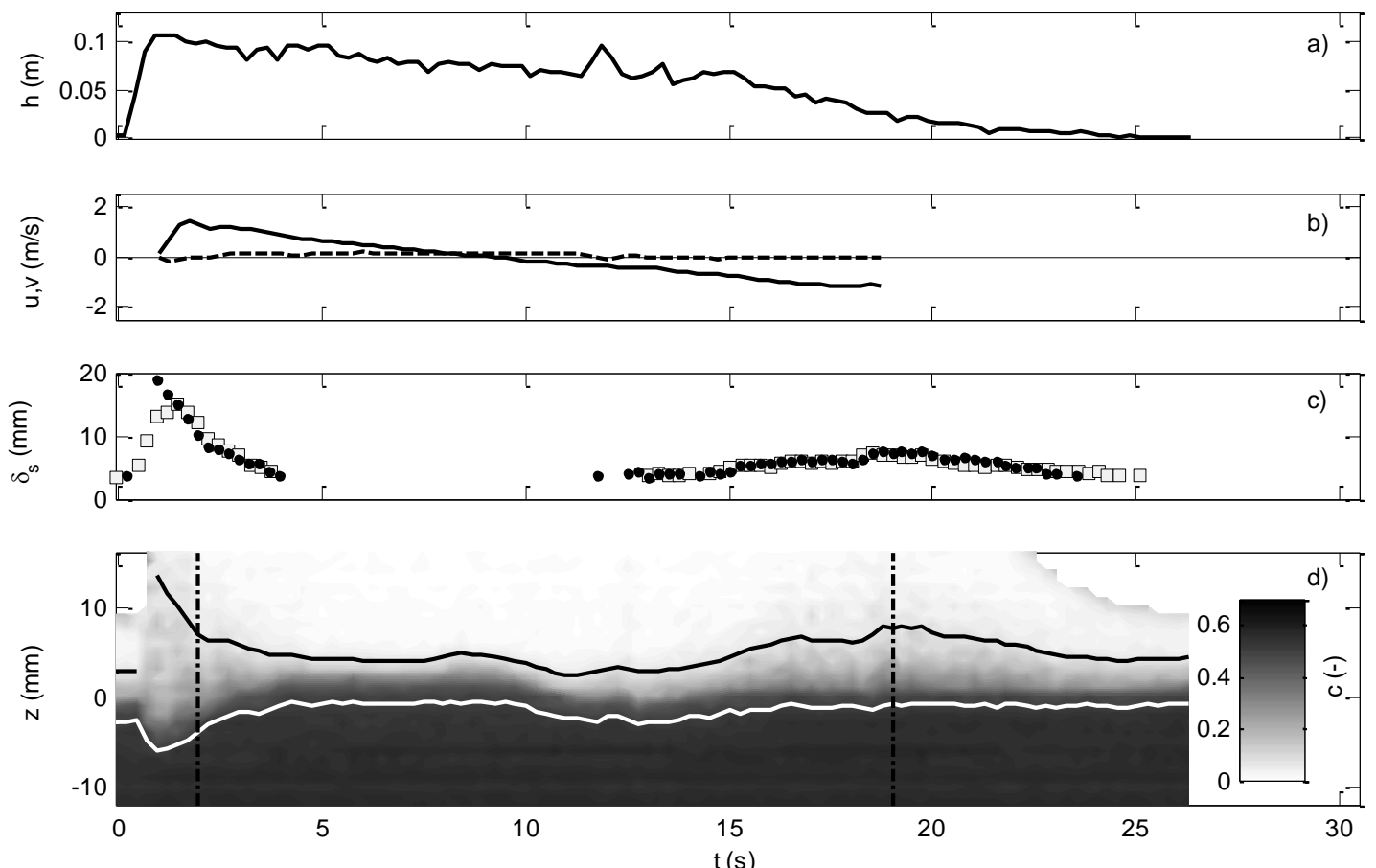

Figure 2. An example swash event. a) Water depth measured by an ultrasonic distance meter. b) Cross-shore (solid line) and along-shore (dashed line) velocity measured by an electromagnetic current meter deployed $0.03 \mathrm{~m}$ above the bed level. c) Sheet thickness measured by two collocated CCP sensors, one displayed as circles, one as squares. d) Sediment concentration time series measured using a CCP. Solid black line displays top of the sheet layer $(c=0.08)$, white line displays bottom of sheet layer $(c=0.51)$. Dash-dotted vertical lines indicate the times of the instantaneous concentration profiles displayed in Figure 3.
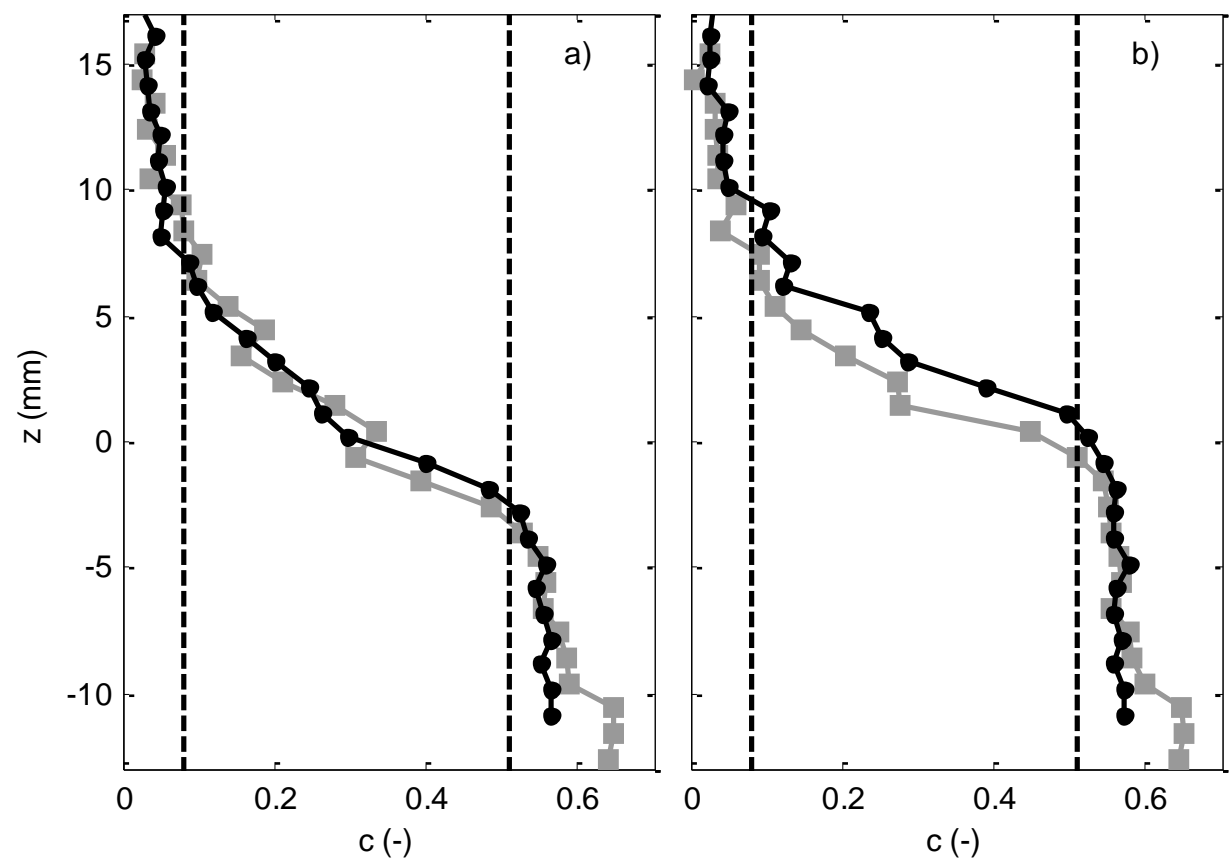

Figure 3. Instantaneous sediment concentration profiles measured by two collocated CCP sensors, displayed as gray squares and black circles respectively. a) During the uprush $(t=1.9 \mathrm{~s})$. b) During the backwash $(t=19.0 \mathrm{~s})$. Cut-off concentration values for top $(c=0.08)$ and bottom $(c=0.51)$ are given by dashed vertical lines. 
In addition to bed shear stress, pressure gradients and bore-advected turbulence are additional potential mechanisms for mobilizing sediment. Sediment motion purely by pressure gradients is referred to as plug flow (Sleath 1999). In the inner surf zone, flow reversal from offshore- to onshoredirected motion is accompanied by a strong onshore-directed pressure gradient and fluid acceleration as a result of wave skewness and asymmetry. A similar effect may occur in the swash zone when a bore arrives at the sensor location, changing the hydrodynamic forcing nearly instantaneously from a nearly dry bed to a bore with a finite water depth and a large onshore-directed velocity. In both cases, significant bore-generated turbulence will affect the bed at roughly the same time as the onshoredirected pressure gradients and the two mechanisms are difficult to separate (Puleo et al. 2000). The large fluid velocities also generate large shear stresses during these events, and pressure gradients, bore-generated turbulence and bed shear stresses will thus act together to mobilize sediment.

Pressure gradients were not measured directly in the present field study, but can be related to the local acceleration using the Euler equation if convective accelerations are neglected. Foster et al. (2006) defined the Sleath number as

$$
S=\frac{\rho \frac{d u_{\infty}}{d t}}{\left(\rho_{s}-\rho_{f}\right) g}
$$

where $\frac{d u_{\infty}}{d t}$ is the time derivative of the free-stream velocity. Sleath (1999) predicted that plug flow will occur for $S \geq 0.29$; Foster et al. (2006) observed in the outer surf zone that plug flow occurs when the Sleath number exceeds 0.1 . To account for the combined effect of shear stress and pressure gradients, Foster et al. (2006) proposed a combined criterion of the form:

$$
\left|-\theta \frac{d_{50}}{h}-S\right| \geq \kappa
$$

where $\kappa$ is a dimensionless constant and $h$ is the height of the plug flow layer.

Figure 4 displays a time series of measurements located at the edge of the inner surf and swash zone, where the water depth only sporadically reaches zero. The Shields number was calculated using equation (1) and by estimating the bed shear stress, $\tau_{b}$, using a quadratic drag law and a friction factor of 0.02 , within the range of previously estimated friction coefficients in the swash zone of a sandy beach (Puleo and Holland 2001; Raubenheimer et al. 2004). Sheet flow events during onshore-directed flow are indicated by light grey bands and occur when a bore arrives at the sensor location. These events display a large onshore acceleration, with the Sleath number occasionally exceeding the threshold value of 0.1 (at $t=5 \mathrm{~s}$ and $t=49 \mathrm{~s}$ ), meaning that according to the criterion of Foster et al. (2006) the pressure gradient at these specific moments in time was capable of mobilizing sediment. The Shields number $\theta$, however, exceeds its threshold for sheet flow $(\theta=1.0)$ by a factor of $2-4$, meaning that while pressure gradients may contribute to the mobilization of sediment, shear stress is clearly the dominant forcing mechanism (Calantoni and Puleo 2006). This Shields number estimate, however, is dependent on the choice of friction factor used in the quadratic drag law.

A second indication that pressure gradients contribute to sediment mobilization is that sheet flow events associated with onshore-directed flow (uprush; indicated in light grey in Figure 4), which typically have a large pressure gradient, have a larger maximum sheet thickness than events associated with offshore-directed flows of similar velocity (backwash; indicated by dark grey rectangles in Figure 4). This is notable, for example, when comparing the uprush event at $14 \mathrm{~s} \leq t \leq 21 \mathrm{~s}$ with the backwash event at $34 \mathrm{~s} \leq t \leq 47 \mathrm{~s}$. The uprush event has a larger maximum sheet thickness, even though the maximum Shields number is comparable for both events. A clear peak in the Sleath number is visible during the uprush event, indicating an onshore-directed pressure gradient, which may explain the larger sheet thickness. Bore-generated turbulence may be an alternative explanation for the larger sheet thickness and further analysis is needed to distinguish both effects.

\section{CONCLUSIONS}

Preliminary results from a field study on swash-zone sediment transport were presented, focusing on measurements of sheet flow using a novel Conductivity Concentration Profiler. An example swash event shows the occurrence of sheet flow during the uprush and the backwash phases of the swash cycle. Instantaneous sediment concentration profiles in the sheet flow layer appear to be roughly linear with a power-law tail at the top of the sheet layer, as in previous studies. Although shear stress is the dominant sediment mobilization mechanism, pressure gradients form a secondary forcing to mobilize 

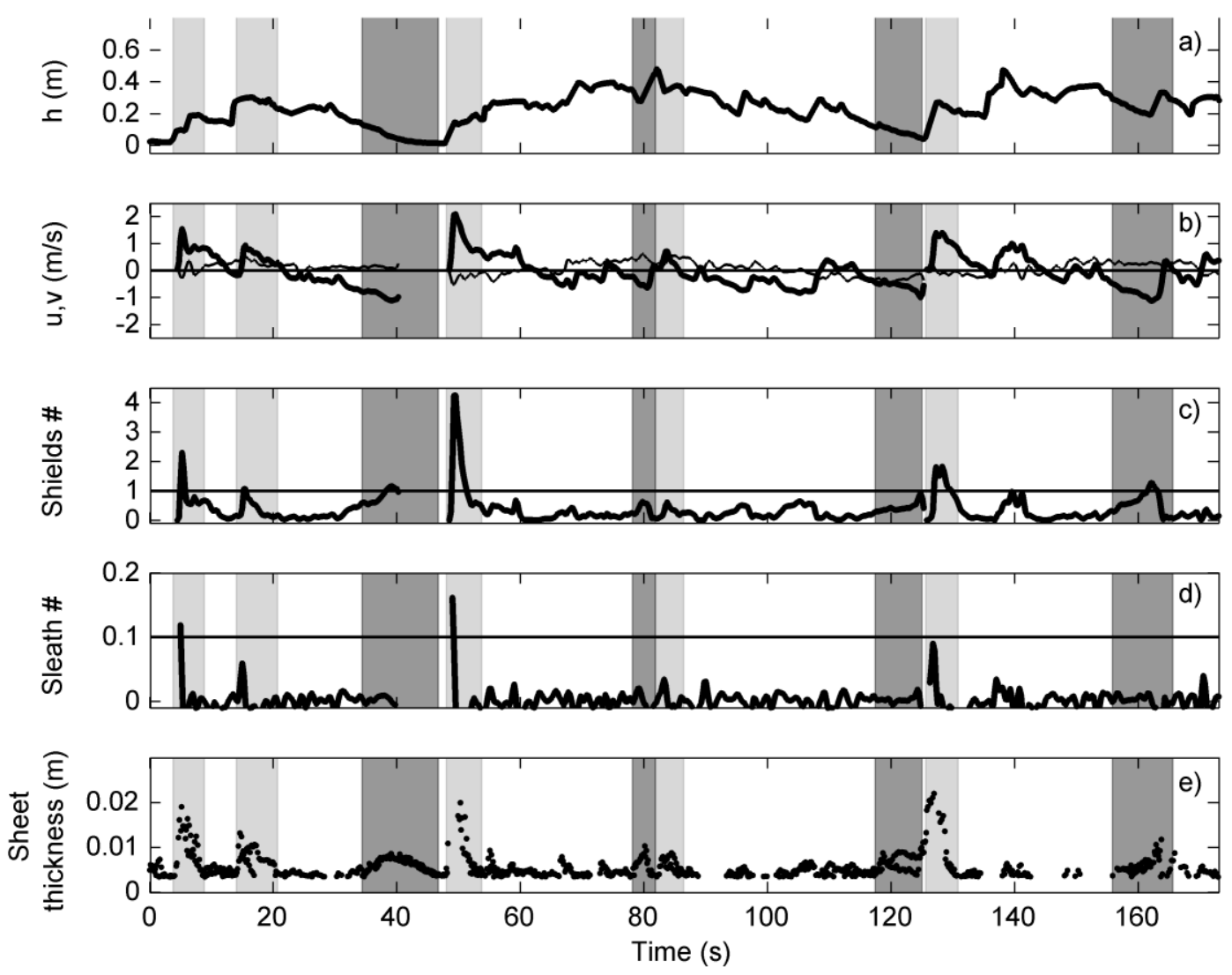

Figure 4. Time series at the edge of the inner surf and swash zone of a) water depth, b) cross-shore (thick line) and alongshore (thin line) velocity, c) Shields number, d) Sleath number, e) sheet thickness. Sheet flow events during onshore-directed flow are indicated by light grey bands, events during offshore-directed motion by dark grey bands. Horizontal lines in c) and d) indicate threshold values for sheet flow and plug flow respectively.

sediment, acting in concurrence with the shear stress. A combined criterion, accounting for both shear stress and pressure gradients, may be better suited to describe sediment mobilization.

\section{ACKNOWLEDGEMENTS}

This material is based upon work supported by the National Science Foundation under Grant No. OCE-0845004. Additional support for this work was provided by the University of Delaware, the Delaware Department of Natural Resources and Environmental Control, the Award for Global Research, Internships, and Performances for Graduate Students at the University of Delaware, the Natural Environmental Research Council, the US-UK Fulbright Commission and the Australian Research Council (DP110101176).

\section{REFERENCES}

Amoudry, L., T.-J. Hsu, and P.L.-F. Liu. 2008. Two-phase model for sand transport in sheet flow regime, Journal of Geophysical Research, 113, C03011.

Archie, G. 1942. The electrical resistivity $\log$ as an aid in determining some reservoir characteristics, Transactions of the American Institute of Mining, Metallurgical and Petroleum Engineers, 146, 54-62.

Bagnold, R.A. 1966. The shearing and dilatation of dry sand and the 'singing' mechanism, Proceedings of the Royal Society of London. Series A. Mathematical and Physical Sciences, 295, 219232.

Bakker, W.T., W.G.M. Van Kesteren, and Z.H. Yu. 1988. Grain-grain interaction in oscillating sheetflow. Proceedings of $21^{\text {st }}$ International Conference on Coastal Engineering, ASCE, 718-731.

Calantoni, J., and J.A. Puleo. 2006. Role of pressure gradients in sheet flow of coarse sediments under sawtooth waves, Journal of Geophysical Research, 111, C01010.

Dohmen-Janssen, C. M., and D. M. Hanes. 2005. Sheet flow and suspended sediment due to wave groups in a large wave flume, Continental Shelf Research, 25, 333-347. 
Drake, T.G., and J. Calantoni. 2001. Discrete particle model for sheet flow sediment transport in the nearshore, Journal of Geophysical Research, 106, 19859-19868.

Foster, D. L., A. J. Bowen, R. A. Holman, and P. Natoo. 2006. Field evidence of pressure gradient induced incipient motion, Journal of Geophysical Research, 111, C05004.

Horikawa, K., A. Watanabe, and S. Katori. 1982. Sediment transport under sheet flow conditions, Proceedings of $18^{\text {th }}$ International Conference on Coastal Engineering, ASCE, 1335-1352.

Hughes, M. G., G. Masselink, and R. W. Brander. 1997. Flow velocity and sediment transport in the swash zone of a steep beach, Marine Geology, 138, 91-103.

Lanckriet, T., J.A. Puleo, and N. Waite. In review. A conductivity concentration profiler for sheet flow sediment transport, IEEE Journal of Oceanic Engineering.

Li, X., and G.C.M. Meijer. 2005. A low-cost and accurate interface for four-electrode conductivity sensors, IEEE Transactions on Instrumentation and Measurement, 54, 2433-2437.

Masselink, G., and J.A. Puleo. 2006. Swash-zone morphodynamics. Continental Shelf Research, 26, 661-680.

Nielsen, P. 1992. Coastal bottom boundary layers and sediment transport. Advanced Series on Ocean Engineering, World Scientific, Singapore, 324 pp.

O’Donoghue, T., and S. Wright. 2004. Flow tunnel measurements of velocities and sand flux in oscillatory sheet flow for well-sorted and graded sands, Coastal Engineering, 51, 1163-1184.

Pugh, F.J., and K.C. Wilson. 1999. Velocity and concentration distributions in sheet flow above plane beds, Journal of Hydraulic Engineering, 125, 117-125.

Puleo, J. A., R.A. Beach, R.A. Holman and J.S. Allen. 2000. Swash zone sediment suspension and transport and the importance of bore-generated turbulence, Journal of Geophysical Research, 105, 17021-17044

Puleo, J.A., and K.T. Holland. 2001. Estimating swash zone friction coefficients on a sandy beach, Coastal Engineering, 43, 25-40.

Puleo, J. A., G. Masselink, P. Russell, I.L. Turner, C.E. Blenkinsopp, D. Buscombe, T. Lanckriet, R. McCall and T. Poate. 2012. Comprehensive study of swash-zone hydrodynamics and sediment transport, Proceedings of 33rd International Conference on Coastal Engineering, ASCE, this volume.

Raubenheimer, B., S. Elgar, and R.T. Guza. 2004. Observations of swash zone velocities: A note on friction coefficients, Journal of Geophysical Research, 109, C01027.

Ribberink, J.S., and A.A. Al-Salem. 1995. Sheet flow and suspension of sand in oscillatory boundary layers, Coastal Engineering, 25, 205-225.

Sleath, J.F.A. 1999. Conditions for plug formation in oscillatory flow, Continental Shelf Research, 1643-1664.

Sumer, B. M., A. Kozakiewicz, J. Fredsoe, and R. Deigaard. 1996. Velocity and concentration profiles in sheet-flow layer of movable bed, Journal of Hydraulic Engineering, 122, 549-558.

Yu, Z., H.D. Niemeyer, and W.T. Bakker. 1990. Site investigation on sand concentration in the sheet-flow layer. Proceedings of $22^{\text {nd }}$ International Conference on Coastal Engineering, ASCE, 23612371.

Wilson, K.C. 1987. Analysis of Bed-Load Motion at High Shear Stress, Journal of Hydraulic Engineering, 113, 97-103. 